\title{
Alice das Coisas: entendendo a comunicação entre objetos na construção de ambientes de aprendizagem
}

\author{
Eliana Alves Moreira ${ }^{1,2}$, M. Cecília C. Baranauskas ${ }^{1}$ \\ ${ }^{1}$ Instituto de Computação \& NIED - Universidade Estadual de Campinas (UNICAMP) \\ Av. Albert Einstein, 1251 - 13.083-852 - Campinas - SP - Brasil \\ ${ }^{2}$ Instituto Federal de São Paulo (IFSP) \\ Av. Salgado Filho, 3501 - 07.115-000 - Guarulhos - SP - Brasil \\ eliana.moreiradifsp.edu.br, cecilia@ic.unicamp.br
}

\begin{abstract}
The widespread presence of things that communicate is a vision of everyday scenario not too far from the present. This work investigates the potential of the Internet of Things as mediator of learning processes in an educational environment. In the scenario proposed, we combine the magic of "things" from fairy tales with the "magic" of contemporary technologies, which embed certain abilities into everyday objects. A scenario and system inspired by Alice in Wonderland were created and exploratory workshops were held in a real educational space. Results suggest how technology can be used to instigate and inspire the construction of narratives, as well as to promote expression skills, formulation, and sequencing of ideas.
\end{abstract}

Resumo. A presença generalizada de coisas que se comunicam constitui uma visão de cenário cotidiano não muito distante do atual. Este trabalho investiga sobre o potencial da Internet das Coisas como mediadora de processos de aprendizagem em ambiente educacional. No cenário proposto, aliamos a magia de "coisas" de contos de fadas à "mágica" das tecnologias contemporâneas, que embutem certas capacidades em objetos cotidianos. Foram criados cenário e sistema inspirados em Alice no País das Maravilhas e realizadas Oficinas exploratórias em espaço educativo real. Resultados sugerem como a tecnologia pode ser usada para instigar e inspirar a construção de narrativas, além de promover habilidades de expressão, formulação e sequenciação de ideias.

\section{Introdução}

A constante miniaturização dos recursos tecnológicos, diminuição dos custos dos dispositivos e aumento da capacidade de processamento dos dispositivos embarcados, têm levado à utilização de tecnologias contemporâneas - dentre elas, as tangíveis e vestíveis - e têm tornado cada vez mais aplicável a diferentes cenários a Internet das Coisas - do inglês, Internet of Things (IoT). A ideia básica da IoT é a presença generalizada à nossa volta de uma variedade de coisas ou objetos - como sensores, atuadores, etiquetas de identificação por radiofreqüência, (do inglês, radio frequency identification - RFID), telefones celulares etc. - que, através de esquemas de endereçamento exclusivos, são capazes de interagir uns com os outros e cooperar com seus vizinhos para alcançar objetivos comuns [Atzori et al. 2010]. As tecnologias de interface vestível referem-se a tecnologias eletrônicas ou computadores que são 
incorporados em artigos de vestuário e acessórios que podem ser confortavelmente usados no corpo e controlados pelo usuário, isto é, o usuário pode executar comandos por meio desses dispositivos vestíveis, mesmo enquanto caminha ou realiza outras atividades [Tehrani e Andrew 2014]. O desenvolvimento de sistemas vestíveis têm se beneficiado da constante miniaturização de componentes e, assim, sistemas têm sido propostos com a intenção de serem imperceptíveis e, como afirma Mann (1997), quase invisíveis, de modo que as pessoas possam se mover e interagir livremente, apoiados por seu domínio de informações pessoais. Geralmente, a tecnologia vestível tem alguma forma de capacidade de comunicação que permite ao usuário acessar informações em tempo real. Em consonância com a utilização de tecnologias contemporâneas que pareçam naturais ao usuário, as tecnologias de interfaces tangíveis dão forma física à informação digital ao empregarem artefatos físicos que, quando manipulados via elementos concretos (como joystick, caneta, brinquedo, entre outros), funcionam como representações e controles para mídia computacional, proporcionando uma interação mais direta do usuário com o sistema, produzindo sistemas interativos que são computacionalmente mediados, mas geralmente não são identificáveis como "computadores" per se [Ishii 2008].

A Internet das Coisas é apresentada por alguns autores como "objetos encantados", uma vez que ela geralmente concede capacidades (escondidas) aos objetos cotidianos [Mcewen e Cassimally 2013]. Assim, contos de fadas podem ser uma boa metáfora para ajudar a compreender possibilidades de ações desses objetos do mundo físico ao se integrarem em um ambiente conectado no qual são capazes de serem identificados, externar seus estados e, eventualmente, possuir capacidade de processamento de tal modo a influenciar outros objetos [Bastos et al. 2016] e até mesmo pessoas. Algumas crianças de hoje, já em contato com as tecnologias contemporâneas citadas, serão os adultos que estarão em pleno contato com dispositivos tecnológicos dos cenários IoT. O design de ambientes educacionais que visam a criatividade e a fantasia podem fazer uso de recursos tecnológicos contemporâneos que explorem a comunicação entre objetos (ou coisas) de modo a enriquecer a experiência da criança e colocá-la em contato com tecnologia de ponta, além de proporcionar uma maneira "mágica" de aprender. Em sintonia com essa ideia, neste trabalho investigamos a utilização de "objetos encantados" e criação de narrativas, com base na obra "Alice no País das Maravilhas" [Carrol Lewis 1865], cujo enredo se passa em um mundo mágico, onde animais e objetos tornam-se "humanizados" e, como tal, passam a falar, andar, ter consciência, a se relacionar uns com outros etc. Baranauskas e Posada (2017, p. 194, tradução nossa), citando diversos outros autores, reforçam a ideia de que a interação tangível para usuário (TUI, acrônimo do inglês, Tangible User Interface) traz benefícios ao processo de aprendizagem: "ambientes baseados em TUI têm o potencial de envolver as crianças ao longo das atividades de aprendizagem evocando fortes sentimentos de alegria e motivação, especialmente importantes nos processos de aprendizagem”.

Diversos autores têm trabalhado a interação entre dispositivos. Por exemplo, Mahmud et al. (2012) desenvolveram o PostBoard, onde os usuários colocam papéis adesivos (com anotações) sobre uma tela que possui uma câmera apontada para ela, incumbida de detectar a aproximação do usuário e captar imagens que, posteriormente, são submetidas a um servidor central. Esse, por sua vez, envia essas imagens para um destinatário, que também possui o PostBoard e, portanto, pode também responder à mensagem recebida utilizando papéis adesivos. Moreira e Baranauskas (2016) investigaram como tecnologias contemporâneas tangíveis - no caso, cartões com RFID - 
VI Congresso Brasileiro de Informática na Educação (CBIE 2017)

Anais do XXVIII Simpósio Brasileiro de Informática na Educação (SBIE 2017)

poderiam ser exploradas em benefício da comunicação e interação social de forma criativa, lúdica e acessível para a maior extensão possível de usuários, através de um jogo onde cartões eram combinados para "comunicar" algo ou para disparar eventos que controlavam regras e configurações de um jogo. Nesses trabalhos, apesar de os objetos interagirem entre si - ou se combinarem para desencadear determinada ação - a Internet não é utilizada.

Neste trabalho, exploramos o conceito de comunicação no universo escolar infantil, buscando entender o sentido que as crianças fazem de "coisas que se comunicam"; nosso objetivo é entender como a Internet das Coisas poderia ser usada como mediadora do processo de aprendizagem. Como base ao estudo exploratório do tema, realizamos o design e desenvolvimento de um ambiente que, na forma de criação de narrativas por meio de objetos vestíveis e tangíveis, foi experimentado em Oficinas com crianças e professores que realimentaram o processo de design do ambiente. Em termos de abordagem pedagógica, as Oficinas apresentadas neste trabalho baseiam-se na abordagem construcionista, de Seymour Papert (1980), que considera que a relação ensino-aprendizagem é mais eficaz quando o aprendiz experimenta a construção de um produto significativo para ele.

As próximas seções estão organizadas da seguinte forma: nas seções 2 e 3 é apresentado o cenário e o estudo exploratório realizado por meio de Oficinas, respectivamente. A seção 4 apresenta as discussões, resultados alcançados e lições aprendidas, e a seção 5 conclui.

\section{Cenário do Estudo}

Como gostaríamos que a tecnologia se parecesse mais natural ao usuário, utilizamos objetos tangíveis disponibilizados pelo ambiente físico e objetos vestíveis (que representavam as fantasias de personagens e objetos da obra "Alice no País das Maravilhas") e denominamos nosso ambiente de "Alice of Things" - AoT. A Figura 1 ilustra alguns materiais e objetos utilizados na criação do cenário.
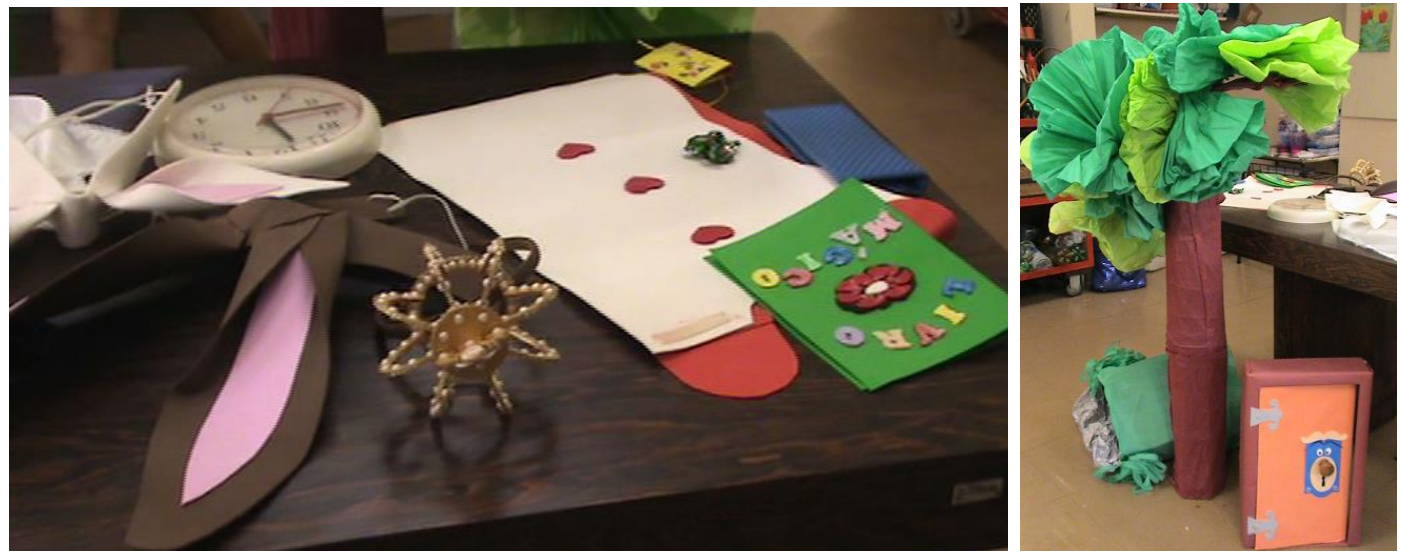

Figura 1. Exemplos de fantasias e objetos construídos para AoT baseados na obra "Alice no País das Maravilhas"

Nesse cenário, o ambiente tecnológico AoT (Figura 2) compõe-se por etiquetas RFID de $13.56 \mathrm{MHz}$, um leitor RFID compatível, um computador, uma saída de som e 
VI Congresso Brasileiro de Informática na Educação (CBIE 2017)

Anais do XXVIII Simpósio Brasileiro de Informática na Educação (SBIE 2017)

um projetor. Cada etiqueta RFID possui um código de identificação único e todo objeto do ambiente AoT possui uma etiqueta RFID. O software foi desenvolvido em Java ${ }^{\mathrm{TM}}$.

O ambiente físico do cenário AoT continha doze objetos ou "coisas": árvore, porta, toca, avental e laço da Alice, livro, orelha e relógio do coelho, orelha da lebre, chapéu do Chapeleiro, coroa da Rainha de Copas e roupa da Carta de Copas. Havia, entre essas coisas, sete comunicações possíveis. Quando duas coisas se comunicavam, mostrava-se no projetor uma imagem com a narração de uma cena envolvendo-as.

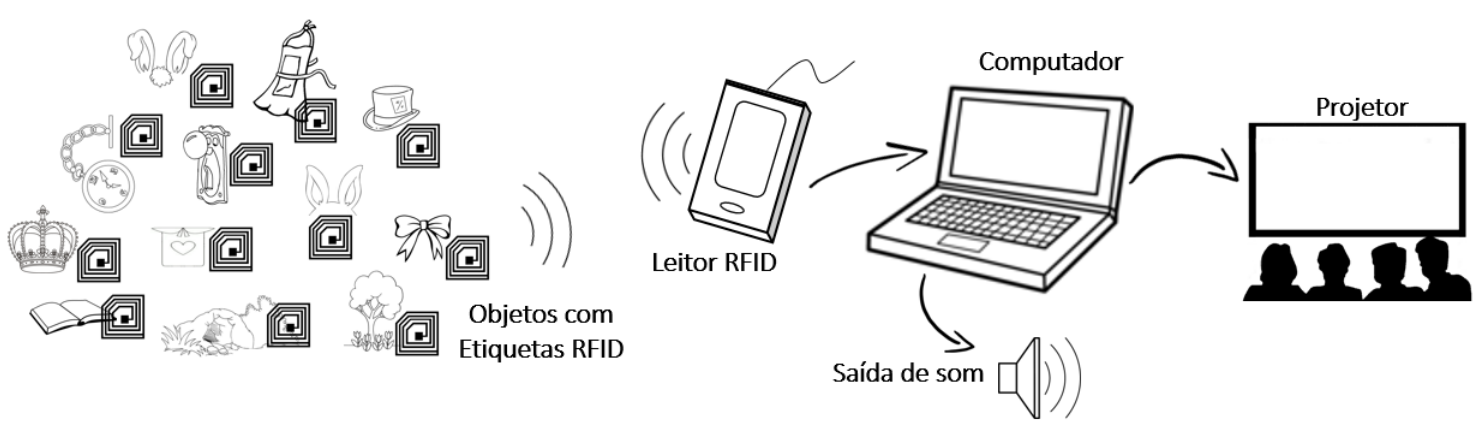

Figura 2. Ambiente tecnológico AoT

Aproximando-se o leitor de RFID de determinado objeto, o participante escolhia os pares que queria combinar; quando as duas últimas coisas escolhidas se combinavam ou, em nosso contexto, se comunicavam, isto é, havia alguma relação entre elas na história da Alice, uma cena que as reunia aparecia no projetor. Por exemplo, ao se aproximar o leitor de RFID da orelha do coelho e logo em seguida do relógio, ou vice-versa, aparecia uma cena no projetor, juntamente com um áudio, onde Alice observa o coelho que corre em direção à toca e diz: "Um coelho vestido como um homem e segurando um relógio??? E parece estar com muita pressa...". Em seguida ouve-se a voz do coelho: "Vou chegar tarde... Não há dúvida, vou chegar tarde!".

No ambiente AoT criado, cada participante poderia vestir-se como um personagem ou uma mistura de personagens, conforme a sua imaginação, uma vez que a escolha de como se caracterizar era livre e, assim, as crianças poderiam utilizar ao mesmo tempo vestíveis característicos de mais de um personagem.

\section{Estudo Exploratório}

\subsection{Contexto e Participantes}

Este trabalho faz parte de um Projeto conduzido junto à Divisão de Educação Infantil e Complementar (DEdIC) da UNICAMP, mais especificamente na unidade do Programa de Desenvolvimento e Integração da Criança e do Adolescente - PRODECAD ${ }^{1}$, que oferece educação suplementar a crianças de 6 a 14 anos, em horário de contraturno ao ensino regular.

\footnotetext{
${ }^{1}$ http://www.dgrh.unicamp.br/dedic/prodecad
} 
VI Congresso Brasileiro de Informática na Educação (CBIE 2017)

Anais do XXVIII Simpósio Brasileiro de Informática na Educação (SBIE 2017)

Foram realizadas três Oficinas ${ }^{2}$ práticas no $2^{\circ}$ semestre de 2016, sendo duas com crianças de 7 a 9 anos e uma com seis professoras, que tinham entre 32 a 55 anos. Cada Oficina teve uma hora e meia de duração; a Oficina 1 e a Oficina 2 com as crianças foram realizadas com um intervalo de uma semana entre elas; as crianças foram organizadas em grupos de maneira que cada uma delas participasse da Oficina 1 ou da Oficina 2. No total, nove crianças participaram da Oficina 1 e outras 11 crianças da Oficina 2.

Para as professoras, as Oficinas acontecem como formação continuada, pois elas realizam as mesmas Oficinas que as crianças e também recebem treinamento em relação aos equipamentos e softwares que fazem parte do estudo, pois a intenção é de que elas possam continuar utilizando, em suas salas de aula, os sistemas e ambientes desenvolvidos, de modo a possibilitar a outras crianças e professores o acesso às tecnologias previamente trabalhadas.

\subsection{Dinâmica das Oficinas}

A dinâmica das Oficinas envolve uma apresentação inicial do seu conceito, dos participantes, objetivos e como ocorrerá o desenvolvimento das atividades por meio do uso de sistemas e artefatos específicos, concebidos para orientar a Oficina e registrar os resultados das atividades.

Inicialmente, o filme "Alice no País das Maravilhas", de 1951, produzido pela The Walt Disney Production, foi assistido pelas crianças, para ambientá-las com o "mundo mágico" proposto em AoT.

As atividades das Oficinas, realizadas em grupos de três participantes, consistiam em encontrar no ambiente coisas (objetos, personagens) que se comunicavam. Após encontrar três desses pares que se comunicavam, o grupo deveria escrever uma narrativa a partir das cenas vistas (Figura 3), utilizando-as em qualquer ordem, podendo complementá-las com novos acontecimentos ou até mesmo modificá-las. Nossa ideia era explorar o uso da tecnologia em uma atividade que trabalhasse formas de aprendizagem, no caso, a construção de narrativas.
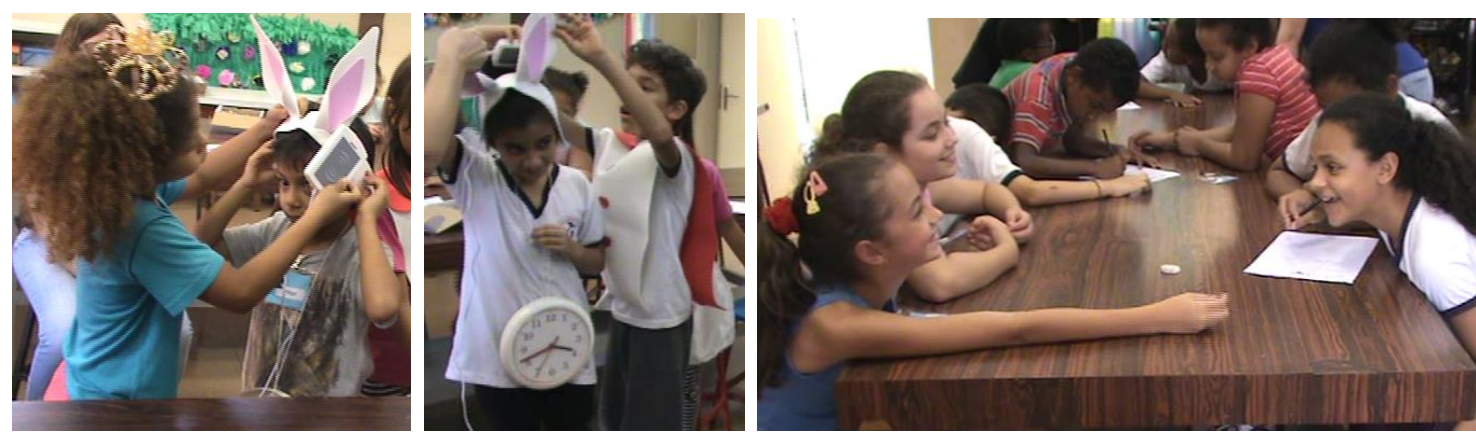

Figura 3. Nas duas fotos à esquerda, crianças descobrindo coisas que se comunicam; à direita, crianças construindo narrativas a partir de cenas vistas

Ao final de cada Oficina, os participantes, por meio de uma autoavaliação, registravam seus estados afetivos relativos às atividades realizadas, emitindo opiniões e sugestões que posteriormente foram analisadas para feedback no desenvolvimento do

\footnotetext{
${ }^{2}$ Projeto aprovado pelo Comitê de Ética em Pesquisa da Unicamp, sob número 32213314.8.0000.5404
} 
VI Congresso Brasileiro de Informática na Educação (CBIE 2017)

Anais do XXVIII Simpósio Brasileiro de Informática na Educação (SBIE 2017)

sistema. Para a avaliação do estado afetivo, foi utilizado o Self-Assessment Manikin (SAM) [Bradley e Lang 1994], uma forma de avaliação pictórica, que possibilita registrar a resposta afetiva em três dimensões: a satisfação, a motivação e o controle do usuário em relação ao sistema. Para aferir a resposta afetiva, o SAM possui como modelo subjacente, o PAD [Russell e Mehrabian 1977] (acrônimo de Pleasure, Arousal, Dominance - neste trabalho tratadas como Satisfação, Motivação e Controle, respectivamente). Nas Oficinas, o SAM foi utilizado de duas formas: impresso em papel e em uma interface com representação tangível [Hayashi et al. 2016], conforme ilustrado na Figura 4.

$\mathrm{Na}$ Oficina 1 com crianças e na Oficina com professores, utilizou-se o SAM em modo impresso, onde cada participante escolheu a imagem que melhor representava o seu nível de satisfação, motivação e controle sobre o sistema. Na Oficina 2 com crianças, os participantes registravam sua resposta afetiva durante as atividades por meio de representações tangíveis dos estados afetivos. Cada representação tangível continha uma identificação oculta proporcionada por meio de cartões RFID, também ocultos. As escolhas dos estados afetivos eram efetivadas aproximando-se o leitor de RFID da representação desejada e logo em seguida utilizando um cartão com uma representação de confirmação. Um áudio associado a cada representação era disparado mediante sua escolha.

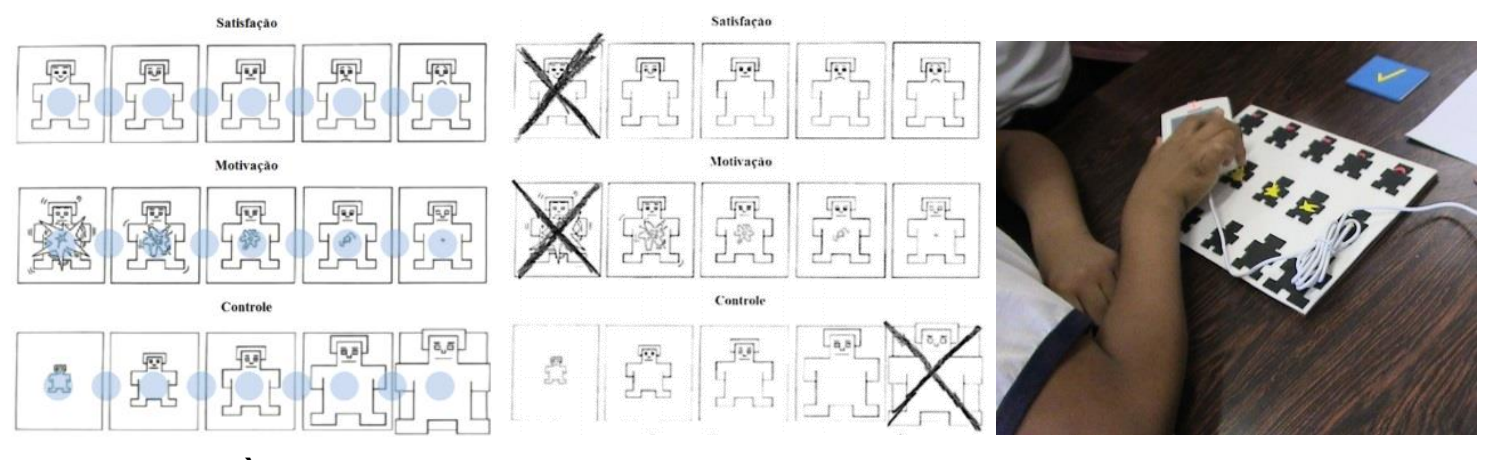

Figura 4. À esquerda, Self-Assessment Manikin - SAM [Bradley e Lang 1994]; no meio, exemplo do SAM (em papel) preenchido por um dos participantes; à direita, um participante utilizando o SAM tangível [Hayashi et al. 2016]

Para a análise dos resultados expressos através do SAM, utilizou-se uma escala de 1 a 9, onde nove significa muito motivado, muito satisfeito ou com muito controle sobre o sistema e um significa pouco motivado, pouco satisfeito ou com pouco controle sobre o sistema. Na representação tangível não havia a possibilidade de se escolher o estado "entre" as imagens, permitida na representação em papel. Porém, para que fosse possível realizar a análise comparativa a partir dessas duas representações do SAM, utilizou-se na representação gráfica dos resultados para o SAM tangível uma escala de 1 a 9, com intervalo de dois em dois.

Todas as Oficinas tiveram a participação de dois a três pesquisadores e foram registradas por fotos e por vídeos, que foram utilizados para análise e observações apresentadas na próxima seção. 


\section{Resultados e Discussão}

A seguir, analisamos a resposta afetiva dos participantes à experiência com o Cenário e sistema criados; segue discussão que aponta para o potencial da Alice das Coisas como mediadora do processo de criação de narrativas.

O primeiro item avaliado foi a dimensão da "Satisfação" (Pleasure no modelo PAD do SAM), que se refere à primeira linha do SAM e reflete quanto de contentamento e alegria o participante sentiu ao participar da Oficina. O gráfico da Figura 5 (esquerda) representa as escolhas dos participantes das duas Oficinas das crianças. Nele é possível observar que $88,5 \%$ do total de participantes ficaram totalmente satisfeitos. Além disso, as crianças deixaram comentários sobre o fato de que gostaram muito de se fantasiar, mostrando que nossa intenção de juntar contos de fada com o "mundo mágico" da AoT possibilitou que o trabalho com escritas de narrativas fosse realizado de maneira lúdica e prazerosa pelas crianças. As professoras, apesar de o gráfico da Figura 5 (direita) não mostrar nenhum valor no extremo ("Satisfação Total" - escala 9), deixaram comentários dizendo que gostaram da atividade por ela trabalhar com narrativas e por possibilitar a criação de histórias completamente diferentes umas das outras a partir das mesmas cenas vistas (por vezes as cenas se repetiam por causa das comunicações de coisas feitas pelos grupos), mostrando que além do potencial de se trabalhar a partir de situações prévias, a tecnologia permite trabalhar a criatividade dos participantes.
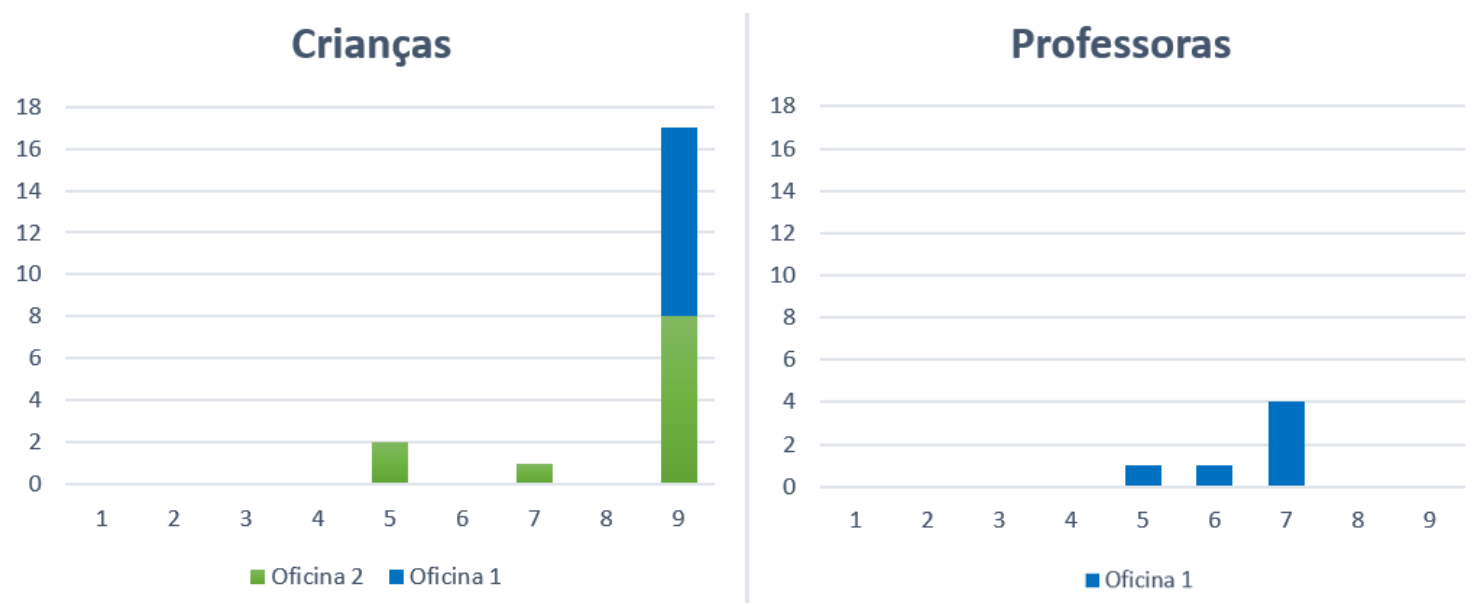

Figura 5. Autoavaliação: dimensão da Satisfação

A dimensão da "Motivação" (Arousal no modelo PAD do SAM), item avaliado por meio da segunda linha do SAM, refere-se a quanto o participante estava envolvido com o objetivo da Oficina e o quanto estava empolgado em participar dela. O gráfico da Figura 6 mostra que a maioria das crianças estava motivada em participar da Oficina, principalmente na Oficina 1, cujos participantes eram mais novos e ficavam bastante entusiasmados em se fantasiarem. No grupo das professoras, foi enfatizado que o manuseio do material, isto é, a tangibilidade e a opção de se vestir sem a lembrança de que a tecnologia está presente, é bastante motivador para a realização da atividade. Isto nos remete à nossa intenção de naturalidade em relação à forma como a tecnologia é trabalhada nas Oficinas e, principalmente, ao nosso estudo exploratório sobre como a IoT poderá potencializar, com seus sensores e atuadores, a comunicação entre as coisas do cenário proposto sem que o ambiente perca sua naturalidade. 

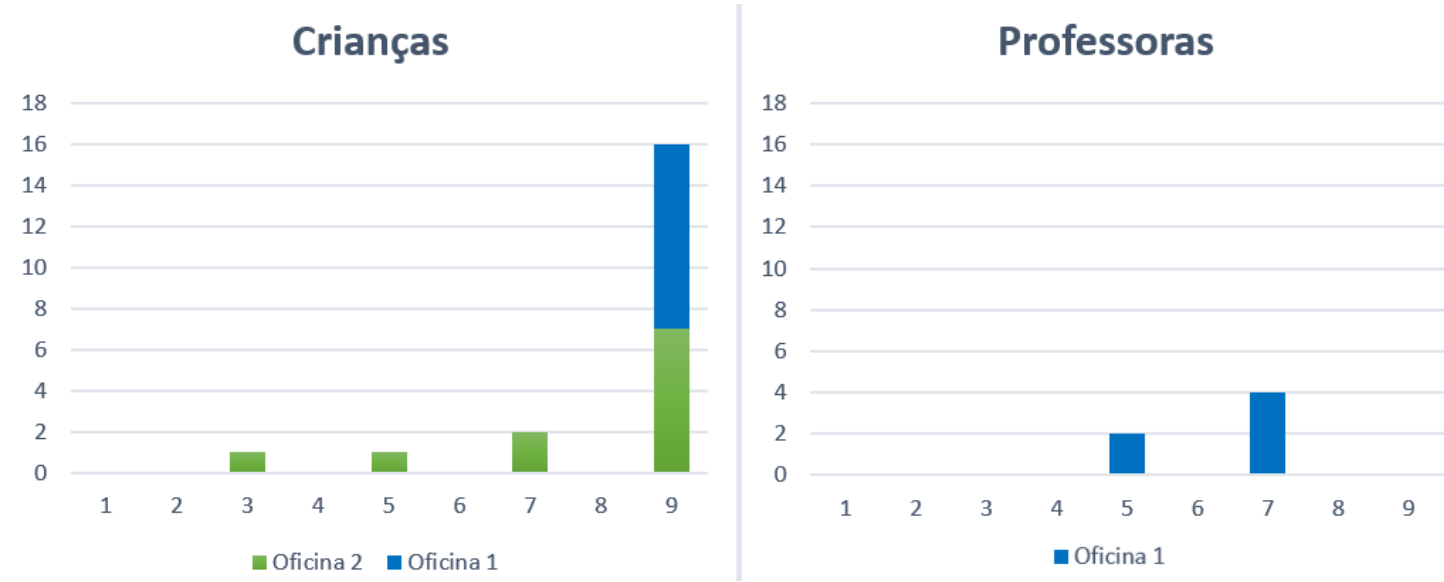

Figura 6. Autoavaliação: dimensão da Motivação

A dimensão do "Controle" (Dominance no modelo PAD do SAM), avaliada por meio da terceira linha do SAM, refere-se ao domínio do participante em relação à utilização do sistema. Podemos observar no gráfico da Figura 7 que a maioria das crianças respondeu que o sistema era de fácil manipulação, embora algumas crianças tenham ficado frustradas em não encontrar comunicações possíveis, traduzindo essa frustração como dificuldade com relação ao sistema. A princípio, as professoras tiveram certa dificuldade em entender que a comunicação se daria entre as duas últimas coisas escolhidas, uma vez que na visão delas as tentativas deveriam sempre ser realizadas de duas em duas coisas, isto é, quando duas coisas não comunicavam, teria que se escolher outras duas. Essa percepção da interação no cenário criado também ocorreu com algumas crianças, que achavam que quando uma comunicação entre duas coisas não ocorria, tinhase que escolher outras duas; certamente esse é um aspecto de revisão do sistema, que não deixava claro que o último objeto escolhido já estaria participando como a primeira escolha na próxima comunicação.
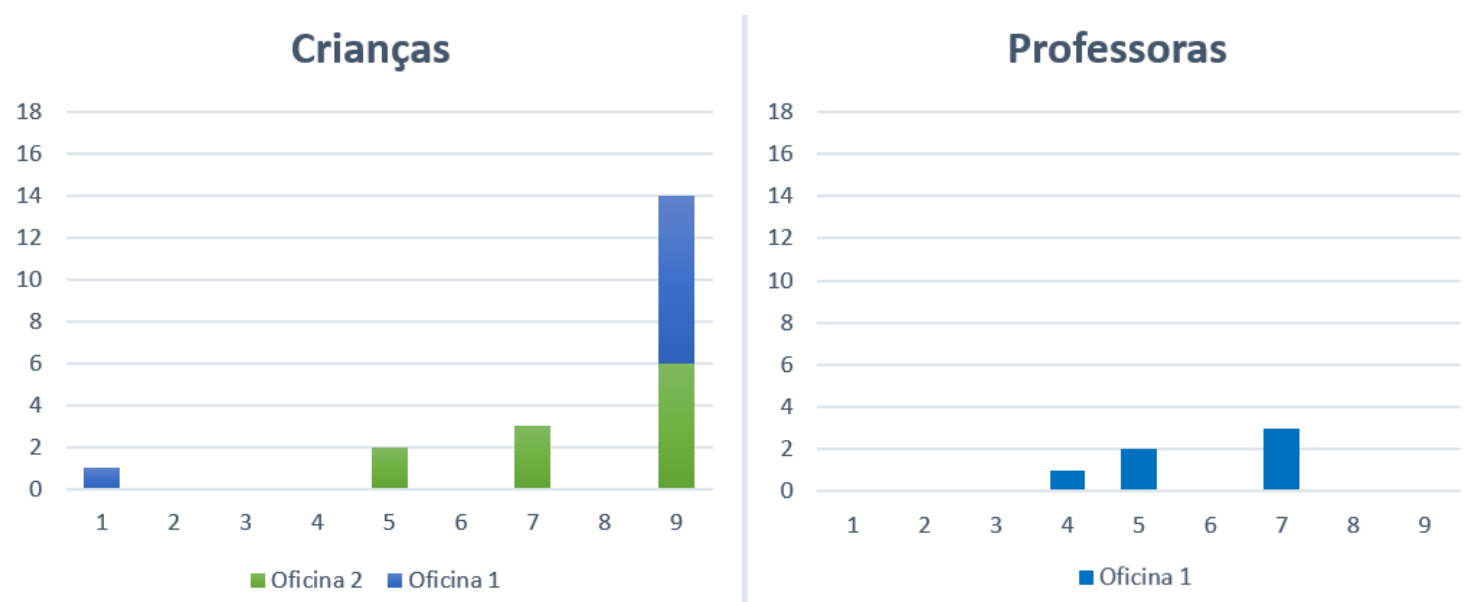

Figura 7. Autoavaliação: dimensão do Controle

No decorrer das Oficinas, observamos que os participantes se envolviam com o ambiente AoT, ficando empolgados em vestir as fantasias e sair em busca de comunicações entre os objetos e/ou personagens do ambiente físico. Baseadas nas lembranças do filme previamente assistido, as crianças inicialmente tentavam fazer comunicarem-se coisas que contracenam no filme, ficando exaltadas quando um colega 
tentava combinar coisas que no filme não estavam em contato, pois queriam "acertar" sempre e conseguir rever a cena. Notamos que algumas crianças queriam que a fantasia que estavam vestindo se comunicasse com alguma outra coisa do cenário, ficando frustradas quando não conseguiam encontrar uma comunicação plausível, fato que não ocorreria se no sistema todos os objetos se comunicassem. Durante a fase de descoberta das comunicações entre as coisas, as crianças colaboravam entre si, dando sugestões para o colega que estava incumbido de encontrar um dos pares, de maneira que ele conseguisse encontrá-lo rapidamente. Estas situações mostram que o ambiente fomenta a colaboração e habilidades de socialização entre as crianças.

A experiência construcionista abordada neste trabalho é demonstrada no fato de que as narrativas, escritas posteriormente à descoberta dos objetos que se comunicam, eram uma reinvenção da criança para a história que era conhecida. Em sua reconstrução, as narrativas nem sempre seguiam a ordem cronológica da história do filme, nem mesmo continham as mesmas cenas, uma vez que, em suas narrativas baseadas nas cenas dos objetos combinados, as crianças muitas vezes inventavam situações totalmente diferentes das apresentadas no filme. Durante a fase de escrita da narrativa, as crianças debatiam a ordem e como a história ficaria, pois, algumas crianças queriam simplesmente transcrever as cenas vistas, mas outras queriam colocá-las em uma determinada ordem cronológica, de modo a dar sentido para a narrativa. Ressaltamos que não tínhamos a intenção de analisar o conteúdo das histórias, a habilidade narrativa das crianças, nem se o estímulo das cenas fazia com que as crianças produzissem melhores histórias ou não. Entretanto, vale a pena observar o aspecto criativo das crianças em revisitar a história vista no filme, sob outros pontos de vista, com a atribuição de novos significados.

Vale a pena observar também que, enquanto um grupo realizava a experiência no cenário, era observado pelas crianças de outro grupo e, quando o grupo em ação não encontrava logo uma combinação plausível, tendia a buscar uma combinação já vista anteriormente. Uma criança sugeriu que todos os participantes das Oficinas pudessem utilizar o cenário ao mesmo tempo, o que talvez resolvesse esse problema, embora criasse outros desafios interessantes do ponto de vista do design do cenário e do sistema.

\section{Conclusão}

Este trabalho investigou sobre a experiência gerada em ambiente educativo com "coisas que se comunicam". Essa experiência é importante para o design de ambientes educativos baseados na Internet das Coisas. Em síntese, os resultados deste trabalho sugerem como a tecnologia pode ser usada para instigar e inspirar a construção de narrativas; além disso, promover a interação social, habilidades de expressão, formulação e sequenciação de ideias. Os comentários deixados nas avaliações sugerem que, sob o ponto de vista das crianças, o mais interessante foi interagir com as coisas, enquanto que para as professoras o mais interessante foi poder usar o cenário de maneira natural para trabalhar a construção de narrativas.

Com o cenário trabalhado nas Oficinas, notamos que o fato de interagir com "coisas que se comunicam" influencia sobre a percepção de outras coisas e pessoas, proporcionando um ambiente colaborativo e rico em possibilidades de criação de atividades para a aprendizagem.

Trabalhos futuros envolvem a consideração da Internet das Coisas no espaço AoT de modo a suscitar a curiosidade das crianças sobre cenários com a comunicação a 
VI Congresso Brasileiro de Informática na Educação (CBIE 2017)

Anais do XXVIII Simpósio Brasileiro de Informática na Educação (SBIE 2017)

distância (via Internet). Neste sentido, também está sendo montada uma arquitetura de rede para que não seja necessário o uso de cabos de energia, que tendem a tornar o ambiente menos natural para o usuário.

\section{Agradecimentos}

Apoiaram este trabalho: CNPq (\#308618/2014-9), FAPESP (\#2015/16528-0), Instituto Federal de São Paulo e Instituto de Computação, Grupo Gestor de Benefícios Sociais e Divisão de Educação Infantil e Complementar da Unicamp.

\section{Referências}

Atzori, L., IerA, A., And Morabito, G. 2010. The Internet of Things: A survey. Computer Networks 54, 15, 2787-2805.

BARANAUSKAS, M.C.C. AND PosAdA, J.E.G. 2017. Tangible and Shared Storytelling: Searching for the Social Dimension of Constructionism. Interaction Design and Children Conference, 193-203.

BASTOS, R.R., LINS, L., AND AMORIM, R.S. 2016. Aperfeiçoando o aprendizado da Libras utilizando elementos de Internet das Coisas. Simpósio Brasileiro de Informática na Educação, 1364-1373.

BRADLEY, M.M. AND LANG, P.J. 1994. Measuring emotion: The self-assessment manikin and the semantic differential. Journal of Behavior Therapy and Experimental Psychiatry 25, 1, 49-59.

CARROL LeWIS. 1865. Alice no País das Maravilhas.

HAYASHI, E.C.S., PosAdA, J.E.G., MAIKE, V.R.M.L., AND BARANAUSKAS, M.C.C. 2016. Exploring new formats of the Self - Assessment Manikin in the design with children. Simpósio Brasileiro sobre Fatores Humanos em Sistemas Computacionais, 1-10.

IsHII, H. 2008. Tangible bits: beyond pixels. Proceedings of the 2nd international conference on Tangible and Embedded Interaction (TEI '08) November, 15-25.

Mahmud, A. Al, Blummel, L., Dijkhuis, S., AND Elberse, I. 2012. Postboard : Freeform Tangible Messaging for People with Aphasia (and other people). .

MANN, S. 1997. Wearable computing: A first step toward personal imaging. Computer $30,2,25-32$.

Mcewen, A. And Cassimally, H. 2013. Design the Internet of Things. Wiley.

MoreirA, E.A. AND BARANAUSKAS, M.C.C. 2016. Investigando processos de comunicação alternativa via tecnologia tangível: um estudo exploratório. XXVII Simpósio Brasileiro de Informática na Educação, 856-865.

PAPERT, S. 1980. Mindstorms: Children, Computers, and Powerful Ideas. New York.

RUSSELL, J.A. AND MEHRABIAN, A. 1977. Evidence for a three-factor theory of emotions. Journal of Research in Personality 11, 3, 273-294.

Tehrani, K. AND ANDREW, M. 2014. Wearable Technology and Wearable Devices: Everything You Need to Know. Wearable Devices Magazine. WearableDevices.com. 